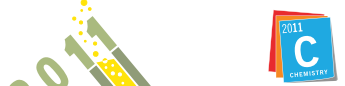

International Year of

CHEMISTRY

\title{
DIFICULDADES CONCEITUAIS NO APRENDIZADO DE EQUILÍBRIOS QUÍMICOS ENVOLVENDO REAÇÕES ÁCIDO-BASE
}

\author{
Mauro Bertotti \\ Instituto de Química, Universidade de São Paulo, CP 26077, 05513-970 São Paulo - SP, Brasil
}

Recebido em 16/2/11; aceito em 27/6/11; publicado na web em 16/8/11

\begin{abstract}
CONCEPTUAL PROBLEMS IN THE LEARNING OF CHEMICAL EQUILIBRIUM THROUGH ACID-BASE REACTIONS. Common student misunderstandings regarding chemical equilibrium are reported taking into account the response of freshman students to some typical questions involving acid-base reactions. Language has been shown to be one of the main issues associated with students' difficulties on this subject, such as in the case of concentration and amount of substance (mol). Another usual problem was observed in questions involving buffer solutions after addition of a reagent. A number of recommendations have emerged from the results presented in this work as an attempt to enhance the learning of this topic in general chemistry courses given to first-year students.
\end{abstract}

Keywords: chemical equilibrium; acid-base reactions; learning difficulties.

\section{INTRODUÇÃO}

A tendência de uma reação química ocorrer pode ser prevista inteiramente com base nas propriedades dos reagentes e produtos à luz das leis da termodinâmica. Isto sugere que aspectos relacionados com o mecanismo ou a velocidade de recombinação dos átomos, à medida que reagentes se transformam em produtos, não são levados em consideração neste nível macroscópico de transformação da matéria. $\mathrm{O}$ sistema atinge uma situação de equilíbrio quando não há tendência de mudança nas quantidades de reagentes e produtos.

Equilíbrios químicos são fundamentais para a compreensão de diferentes aspectos da transformação de substâncias químicas como, por exemplo, em processos industriais, biológicos e ambientais. A abrangência do tema faz com ele seja recorrente em diversas disciplinas de Química, quer seja no nível qualitativo quanto no quantitativo. A dificuldade da transmissão de conhecimentos relacionados a equilíbrios químicos de maneira conceitual e consistente é claramente reconhecida por professores do Ensino Médio e Superior. ${ }^{1-5}$ Especialmente no Ensino Médio, a invocação do princípio de Le Chatelier ("fuga ante a força") é recorrente e induz os alunos a graves erros conceituais como, por exemplo, a noção de que o sistema responde a um estímulo causando mudanças nas concentrações das espécies envolvidas, mas depois retorna à situação inicial para contrabalançar a ação exercida inicialmente. ${ }^{6,7}$ Muitas vezes a resposta certa a um questionamento é obtida empregando-se este princípio, embora a justificativa seja cientificamente inapropriada. Um exemplo consiste na transformação da espécie $\mathrm{Co}\left(\mathrm{H}_{2} \mathrm{O}\right)_{6}{ }^{2+} \mathrm{em} \mathrm{Co}(\mathrm{SCN})_{4}{ }^{2-}$, muito usada em Química Analítica Qualitativa para a identificação de íons Co(II). Ao analisar a equação que representa este equilíbrio

$\mathrm{Co}\left(\mathrm{H}_{2} \mathrm{O}\right)_{6}{ }^{2+}+4 \mathrm{SCN}^{-} \rightleftharpoons \mathrm{Co}(\mathrm{SCN})_{4}{ }^{2-}+6 \mathrm{H}_{2} \mathrm{O}$

vários alunos acertadamente respondem que a adição de água ao sistema desloca o equilíbrio para a formação da espécie $\mathrm{Co}\left(\mathrm{H}_{2} \mathrm{O}\right)_{6}{ }_{6}^{2+}$. Entretanto, a justificativa usualmente oferecida evoca o deslocamento

e-mail: mbertott@iq.usp.br do equilíbrio para a esquerda como resposta à adição de um "reagente" presente no lado direito. Como a atividade (ou concentração) da água é invariável, essa explicação não é correta e são poucos os estudantes que percebem a influência da diluição (diminuição da concentração das espécies químicas pela adição do solvente) no deslocamento do referido equilíbrio.

Outro exemplo bastante evidente do uso inapropriado do princípio de Le Chatelier fica evidenciado ao se fazer uma análise das respostas de ingressantes nos cursos de Química do IQUSP, aos quais tem sido aplicada uma prova na primeira semana de aulas com o objetivo de avaliar o nível de conhecimentos em conceitos básicos de Química. ${ }^{8}$ Uma das questões é a seguinte:

Considere o seguinte sistema no equilíbrio:

$$
\mathrm{N}_{2}(\mathrm{~g})+3 \mathrm{H}_{2}(\mathrm{~g}) \rightleftharpoons 2 \mathrm{NH}_{3}(\mathrm{~g})
$$

A aplicação de uma pressão crescente, apenas no lado esquerdo, fará com que o equilíbrio se desloque para a direita. Esta afirmação a) está correta em qualquer circunstância.

b) está correta se a amônia for continuamente removida.

c) está correta, se a reação for endotérmica.

d) descreve ação impraticável.

e) não está correta. O equilíbrio se deslocará para a esquerda.

Por se tratar de ingressantes, o índice de respondentes é geralmente muito alto (em torno de $80 \%$ ) e das 25 questões da referida avaliação, esta é a que tem consistentemente apresentado os maiores índices de respostas erradas, provavelmente porque os estudantes associam, de maneira impensada e precipitada, a ação sugerida a um aumento da pressão total no sistema. Acreditam, portanto, que no sistema proposto há uma nítida divisão entre reagentes e produtos (proporcionada pela dupla seta), sendo possível, desta maneira, influenciar isoladamente somente um dos lados separados pela dupla seta. ${ }^{3,9}$ Ainda sobre este assunto, cabe citar a confusão sobre o termo "pressão total no sistema" sem variação de volume (por exemplo, pela introdução de um gás inerte) e direta aplicação do princípio de 
Le Chatelier na resolução de problemas envolvendo espécies gasosas. Nestes casos, a lei da "ação-reação" é empregada de maneira mecânica e incorreta pelos alunos, sem o devido estabelecimento de relações com propriedades mensuráveis e consideração dos aspectos necessários para a compreensão de sistema no equilíbrio químico em níveis molecular e atômico.

A noção de que o equilíbrio consiste em sistema estático, em que as reações nos dois sentidos deixam de se processar, é muitas vezes utilizada pelos estudantes na busca de analogias com situações do cotidiano como, por exemplo, o ponteiro de uma balança. Cabe ressaltar, como reforço ao citado exemplo, a incapacidade de vários estudantes na distinção entre equilíbrio físico e equilíbrio químico. ${ }^{10}$ Mesmo para aqueles que percebem a natureza dinâmica do equilíbrio, a ideia de que num equilíbrio químico as reações nos dois sentidos podem ser vistas como eventos independentes e com velocidades diferentes ainda é bastante difundida. Muitos estudantes são hábeis na realização de cálculos envolvendo equilíbrios químicos mediante o emprego de algoritmos previamente assimilados, entretanto fracassam ao tentar explicar conceitualmente as mudanças que ocorrem no sistema estudado. ${ }^{11-13}$

Visto que existem evidentes falhas na compreensão de aspectos conceituais e qualitativos sobre o equilíbrio químico, não é surpreendente que os alunos tenham dificuldades para abordar o assunto quantitativamente. No presente artigo são apresentados dados sobre o desempenho de estudantes ingressantes no curso de Bacharelado e Licenciatura do IQUSP em questões que versam sobre equilíbrios ácido-base no âmbito de uma disciplina introdutória de Química. O conceito de acidez e medidas de $\mathrm{pH}$ é bastante importante, tanto em nível acadêmico quanto no industrial, como pode ser constatado pela atenção dada ao tema neste periódico. ${ }^{14-16}$ No que tange à área de ensino em nível superior, o assunto tem relevância destacada devido à sua relação direta com várias disciplinas usualmente pertencentes a uma típica grade curricular de um curso de Química ou de áreas afins.

Desta forma, no presente estudo pretendeu-se avaliar a existência de correlação entre as dificuldades na assimilação de alguns conceitos qualitativos e quantitativos e deficiências e concepções erroneamente incorporadas pelos estudantes desde o Ensino Médio. Algumas reflexões sobre o ensino deste tema em disciplinas introdutórias no Ensino Superior são apresentadas como conclusão do trabalho.

\section{O CONTEXTO DO TRABALHO}

Conforme já frisado anteriormente, o presente estudo foi desenvolvido tomando como base o desempenho de ingressantes no IQUSP em 2007. Estes alunos foram selecionados pela FUVEST em carreira cuja demanda tem alcançado uma razão candidato/vaga ligeiramente maior do que 10 nos últimos anos. Um dos exames da segunda etapa do processo seletivo no referido ano consistiu em prova de Química e a análise das notas dos estudantes demonstra que a heterogeneidade era bastante grande no que diz respeito ao desempenho nesta avaliação. Cabe ressaltar que o programa de Química do vestibular apresenta muitos pontos em comum com o conteúdo programático de uma das disciplinas introdutórias do curso de Química denominada Fundamentos da Química - Transformações, em que os temas são, obviamente, tratados num nível cognitivo mais elevado.

O objetivo geral da referida disciplina é apresentar aos alunos uma visão macroscópica da matéria, em que conceitos gerais de reatividade, termodinâmica e velocidade das reações químicas são discutidos em associação com aulas práticas. Os experimentos envolvendo estes assuntos são realizados com a dupla função de reforçar o aprendizado e introduzir as técnicas básicas de trabalho prático. $\mathrm{Na}$ ementa da referida disciplina incluem-se tópicos de um curso clássico de Química Geral, como estados da matéria, mol e massa molar, equações químicas, solubilidade, equilíbrios químicos, reações químicas, termoquímica, eletroquímica e cinética.

Um dos assuntos que compõem a disciplina, conforme já mencionado, relaciona-se ao conceito de equilíbrios ácido-base e, num nível um pouco mais avançado, aspectos envolvendo a preparação e propriedades de soluções-tampão. No $1^{\circ}$ semestre de 2007 o assunto foi abordado em aproximadamente 10 aulas teóricas de $2 \mathrm{~h}$ e em 3 experimentos de 3 a 4 h. Trata-se de conteúdos especialmente importantes para disciplinas subsequentes na grade curricular de um curso de Química como, por exemplo, ao se estudar aminoácidos, relação entre estrutura e pK de compostos orgânicos, termodinâmica, dentre outros assuntos. Em disciplinas de Química Analítica, em que o desenvolvimento em níveis teórico e prático exige uma abordagem quantitativa não só de equilíbrios ácido-base, mas também de precipitação, oxirredução e complexação, o tema é ainda mais recorrente. Docentes que ministram disciplinas de Química Analítica têm continuamente manifestado o descontentamento com o despreparo dos alunos no que tange a aspectos relativos ao tratamento quantitativo de equilíbrios, tema essencial ao se tratar da separação seletiva de cátions pelo controle do $\mathrm{pH}$ ou em titulações. A falta de habilidade dos alunos ao lidar com estes conteúdos exige dos docentes um investimento de tempo adicional, que muitas vezes requer a subtração de tópicos julgados importantes em Química Analítica.

No contexto acima assinalado, algumas impressões sobre as dificuldades manifestadas pelos estudantes na resolução de problemas inseridos em provas a eles aplicadas no $1^{\circ}$ semestre de 2007 são apresentadas a seguir, ano em que a disciplina introdutória Fundamentos da Química - Transformações teve a participação do autor deste artigo como docente. Cumpre enfatizar que o desempenho dos alunos em provas constitui-se no instrumento utilizado no presente trabalho para aferir a aquisição e manuseio de novos conhecimentos. Esta premissa é provavelmente válida, pois o estímulo proporcionado por uma prova exige do aluno um total comprometimento com seu aprendizado.

Na disciplina Fundamentos da Química - Transformações, o conhecimento dos alunos sobre equilíbrios ácido-base foi avaliado na $2^{\mathrm{a}}$ prova teórica com 3 questões e em uma questão da $3^{\mathrm{a}}$ prova teórica. Abaixo seguem, a título de ilustração, duas questões da $2^{a}$ prova teórica e a questão sobre equilíbrios químicos da $3^{\mathrm{a}}$ prova teórica:

Uma reação enzimática foi conduzida em tampão HTris/Tris (200 mL), onde Tris corresponde à base fraca tris(hidroximetil) aminometano e HTris ${ }^{+}$é o ácido conjugado $\left(\mathrm{pK}_{\mathrm{a}}=8,1\right)$. O pH da solução no início da reação era 7,8. Como resultado dessa reação, $0,001 \mathrm{mols}$ de $\mathrm{H}^{+}$foram produzidos. Sabendo que a quantidade total de Tris em solução (Tris + HTris ${ }^{+}$) corresponde a 0,12 mols, calcule:

a) a composição do tampão no início da reação (concentrações de Tris e HTris ${ }^{+}$

b) o pH após o término da reação.

c) o pH após o término da reação caso a solução não estivesse tamponada (sem Tris e HTris ${ }^{+}$).

Um dos tampões que regulam o $\mathrm{pH}$ do sangue é constituído por mistura de $\mathrm{CO}_{2}$ e $\mathrm{HCO}_{3}{ }^{-}$. Considerando que a concentração destas espécies no fluido sanguíneo seja 1 e $20 \mathrm{mmol} \mathrm{L}^{-1}$, respectivamente,

a) Calcule o $\mathrm{pH}$ deste fluido e defina qual é a espécie predominante, nestas condições, do aminoácido alanina $\mathrm{CH}_{3} \mathrm{CH}\left(\mathrm{NH}_{2}\right)$ COOH. Dados: $\mathrm{pK}_{\mathrm{a}}$ do aminoácido: 2,35 e 9,69.

b) Represente num diagrama de distribuição a porcentagem de participação de cada uma das diferentes formas da alanina em função do $\mathrm{pH}$.

(Considere para $\mathrm{H}_{2} \mathrm{CO}_{3}, \mathrm{~K}_{1}=7,8 \times 10^{-7}, \mathrm{~K}_{2}=4,7 \times 10^{-11}$ ) 
Um béquer contém $100 \mathrm{~mL}$ de uma solução de $\mathrm{MgCl}_{2} 0,1 \mathrm{~mol} \mathrm{~L}^{-1}$

a) Determine o $\mathrm{pH}$ a partir do qual começa a precipitação de $\mathrm{Mg}(\mathrm{OH})_{2}\left(\mathrm{~K}_{\mathrm{s}}=4,0 \times 10^{-11}\right)$.

b) Calcule a concentração de TODAS as espécies químicas remanescentes na solução após a adição de $100 \mathrm{~mL}$ de uma solução de $\mathrm{NaOH} \mathrm{0,2} \mathrm{mol} \mathrm{L}^{-1}$.

c) Ocorre precipitação de $\mathrm{MgCO}_{3}\left(K_{s}=3,5 \times 10^{-8}\right)$ se a solução de $\mathrm{MgCl}_{2}$ for saturada com $\mathrm{CO}_{2}\left(\right.$ Massa Molar $\left.=44 \mathrm{~g} \mathrm{~mol}^{-1}\right)$ ? Considere que a solubilidade do gás em água é 1,67 $\mathrm{g} \mathrm{L}^{-1}$ a $20^{\circ} \mathrm{C}\left(\mathrm{H}_{2} \mathrm{CO}_{3}, \mathrm{~K}_{1}=7,8 \times 10^{-7}, \mathrm{~K}_{2}=4,7 \times 10^{-11}\right)$.

\section{RESULTADOS E DISCUSSÃO}

\section{O tampão Tris/HTris ${ }^{+}$}

O desempenho dos alunos na questão referente ao tampão Tris/ HTris $^{+}$pode ser avaliado observando-se os dados apresentados na Figura 1. Percebe-se claramente a grande variação no índice de acertos, ratificando a heterogeneidade da turma, já detectada anteriormente. A existência de eventual correlação entre o desempenho dos estudantes nessa questão e na prova de Química da FUVEST foi também investigada, e os resultados obtidos demonstram que ela é muito baixa $(\mathrm{r}=0,20)$, demonstrando que o vestibular não é necessariamente preditivo. Certamente há muitos outros fatores com papel eventualmente até mais importante do que a formação prévia dos estudantes no Ensino Médio (supostamente aferida no vestibular), dentre os quais podem ser destacados a adaptação ao ambiente universitário, nível de envolvimento com o curso, relaxamento natural após o vestibular, dentre outros. Cumpre salientar que estes aspectos estão intimamente relacionados com a evasão em cursos universitários, em concordância com levantamento detalhado apresentado na literatura no que diz respeito a cursos de Química. ${ }^{17}$

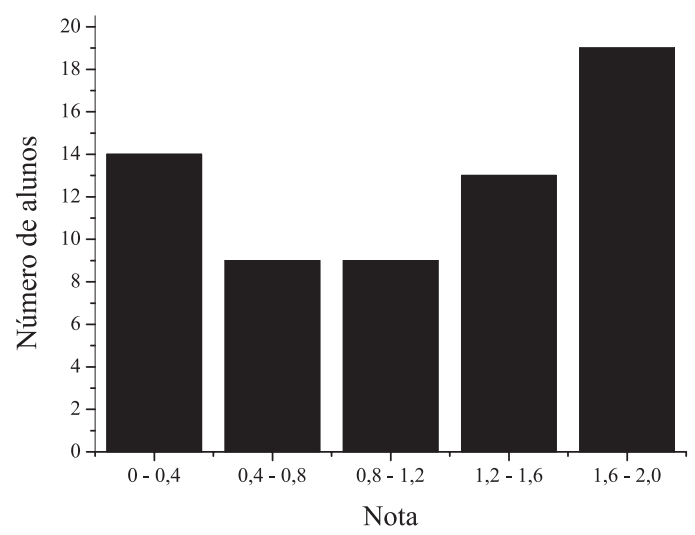

Figura 1. Desempenho dos ingressantes do curso de Bacharelado e Licenciatura em Química (2007) na $3^{a}$ questão da $2^{a}$ prova teórica da disciplina Fundamentos da Química - Transformações (questão descrita no texto, nota máxima $=2,0$ pontos)

A análise das respostas dos estudantes à questão sobre o tampão Tris/HTris ${ }^{+}$revela dados importantes para uma primeira explicação sobre as dificuldades de aprendizagem de assuntos relacionados a equilíbrios químicos, especificamente no que concerne ao tema ácido-base e soluções-tampão. A avaliação mais apurada das respostas aos vários itens da questão permite concluir que a maior parte dos estudantes conseguiu associar o sistema químico proposto (solução contendo HTris $^{+}$e Tris) a uma solução com as características de solução-tampão, em que um ácido fraco coexiste com sua base conjugada. De posse do valor do $\mathrm{pH}$ da solução, os alunos conseguiram satisfatoriamente chegar à composição do sistema apresentado. Entretanto, uma fração reduzida prosseguiu com sucesso na resolução do problema que, no segundo item, requeria uma habilidade cognitiva mais elevada. Exemplos típicos de deficiências notadas na correção deste item envolveram a dificuldade de identificação da reação química entre o ácido produzido no processo enzimático e a base Tris e confusão entre concentração e quantidade de matéria expressa em mols. A média da turma nesta questão foi 1,1 (numa escala de 0 a 2,0).

\section{$\mathrm{O}$ sistema $\mathrm{H}_{2} \mathrm{CO}_{3} / \mathrm{HCO}_{3}{ }^{-} / \mathrm{CO}_{3}{ }^{2-}$}

Os problemas apontados na questão sobre o tampão Tris/HTris ${ }^{+}$ também foram consistentemente observados em outra questão da $2^{\mathrm{a}}$ prova teórica, a qual abordava o equilíbrio de espécies pertencentes a um sistema de interesse biológico. $\mathrm{O}$ desempenho da turma também ficou próximo de $50 \%$ e foram feitos questionamentos sobre $\mathrm{pH}$, grau de dissociação, grau de protonação de aminoácidos adicionados à solução em função do pH e eficiência do sistema na manutenção do pH após a adição deliberada de quantidade fixa de ácidos ou bases fortes.

Nesta questão, foram observadas dificuldades adicionais envolvendo nomenclatura, pois no enunciado empregou-se o termo $\mathrm{CO}_{2}$ (e não $\mathrm{H}_{2} \mathrm{CO}_{3}$ ), de forma que muitos alunos confundiram $\mathrm{CO}_{2}$ com $\mathrm{CO}_{3}{ }^{2-}$. Em função dessa falha de interpretação, a clara proposição de um sistema tampão governado pelo equilíbrio

$$
\mathrm{H}_{2} \mathrm{CO}_{3} \rightleftharpoons \mathrm{H}^{+}+\mathrm{HCO}_{3}
$$

não era evidente para a maioria dos alunos, e isso pode ser compreendido pelo fato de que alguns assumiam como única espécie presente na solução o $\mathrm{HCO}_{3}^{-}$(e calcularam o pH da solução empregando a expressão clássica relacionada à média aritmética dos $\mathrm{pKs}$ ).

\section{Equilíbrios ácido-base e de precipitação}

O desempenho mais fraco dos estudantes foi observado em uma questão sobre equilíbrios químicos introduzida na $3^{\text {a }}$ prova teórica. Por envolver a associação entre equilíbrios ácido-base e precipitação, assim como por outros motivos a seguir explicitados, a média da classe nesta questão ficou em torno de 0,7 (na escala de 0 a 2,0). Afora problemas já apontados anteriormente, especialmente aqueles envolvendo confusão entre concentração e quantidade de matéria, o baixo índice de acertos nesta questão pode ser caracterizado pelas seguintes falhas conceituais: inclusão do sólido $\mathrm{Mg}(\mathrm{OH})_{2}$ na expressão do equilíbrio; dificuldade no cálculo da concentração de $\mathrm{H}_{2} \mathrm{CO}_{3}$ em mol L-1 a partir do dado de solubilidade do $\mathrm{CO}_{2}$; dificuldade de associação entre $\mathrm{CO}_{2}$ e $\mathrm{H}_{2} \mathrm{CO}_{3}$; a composição do sistema químico não foi claramente reconhecida após a adição de base ao sistema; não foi evidente, para boa parte dos estudantes, que uma solução de $\mathrm{H}_{2} \mathrm{CO}_{3}$ contém íons $\mathrm{CO}_{3}^{2-}$ em concentração passível de cálculo.

Um detalhe a ser ressaltado após análise cuidadosa das respostas dadas pelos alunos às questões discutidas neste trabalho diz respeito a erros em cálculos matemáticos (erros algébricos e não de formulação de estequiometrias). Durante a correção foram observados alguns deslizes por esquecimento ou distração, mas certamente o fraco desempenho dos alunos não tem relação com esta deficiência. De fato, isso seria surpreendente, visto que as operações são suficientemente elementares para alunos selecionados por exame de seleção tão rigoroso quanto o da FUVEST.

Parece evidente pela análise das respostas dos alunos que um empecilho significativo, desprezado pela maioria dos professores, refere-se à falta de costume com a "linguagem química" e diagnóstico parecido tem sido relatado na literatura. ${ }^{4,9}$ Exemplo típico foi observado em respostas de alunos de reconhecida capacidade, muitos dos quais calcularam com 
naturalidade a concentração da espécie $\mathrm{Mg}(\mathrm{OH})_{2}$. Embora estes alunos provavelmente saibam que espécies químicas no estado sólido não fazem parte da expressão de equilíbrio, eles assim procederam porque não reconheceram o $\mathrm{Mg}(\mathrm{OH})_{2}$ como sólido! A confusão é ainda mais justificada uma vez que, durante o curso, são feitos comentários sobre a formação de espécies complexas, como é o caso da dissolução de $\mathrm{Zn}(\mathrm{OH})_{2} \mathrm{com}$ excesso de base forte. A natureza de espécies químicas em solução não é trivial para alunos ingressantes, e essa lacuna de conhecimento é responsável, em grande parte, pelo desempenho não satisfatório dos estudantes em problemas envolvendo equilíbrios químicos. De maneira oposta, a assimilação de outros conceitos abordados em disciplinas de Química Geral como soluções, estequiometria, cinética ou termodinâmica é menos difícil, pois os ingressantes já têm boa familiaridade com esses assuntos no Ensino Médio ou o tratamento dado a esses tópicos é mais superficial em cursos introdutórios.

\section{CONCLUSÕES}

Os dados obtidos neste estudo ratificam observações de diversos autores sobre a dificuldade do aprendizado de equilíbrio químico, tanto no que diz respeito a aspectos de caráter mais conceitual quanto aos associados a um tratamento quantitativo do assunto. Na verdade, essa distinção não é tão nítida, pois em muitos casos a resolução de problemas sobre o tema exige uma prévia caracterização ou compreensão do sistema estudado e como ele responde a influências exercidas mediante a adição de novos reagentes ou mudanças nas concentrações de seus componentes.

A análise das informações apresentadas leva à conclusão de que o aprendizado de conceitos com os quais os estudantes iniciantes em cursos de graduação não estão familiarizados e o nível de abstração e a linguagem empregada dificultam a assimilação dos conteúdos ministrados. Em muitas situações, a simplificação dos conteúdos com o intuito de facilitar o aprendizado é prejudicial, porque induz os estudantes a conclusões errôneas sobre a concentração das espécies químicas em solução, conforme explicitado em diversos artigos referentes a equilíbrios de solubilidade. ${ }^{18-20}$

Uma abordagem com forte predominância conceitual do problema é muito mais vantajosa e produtiva em cursos introdutórios, podendose transferir o tratamento quantitativo mais rigoroso para disciplinas avançadas e para estudantes com mais maturidade, os quais já possuem certo grau de intimidade com a "linguagem química" e estão motivados a empreender esforços no aprendizado destes tópicos em função de demandas de outras disciplinas (como, por exemplo, Química Analítica). Neste sentido, cabe ressaltar o papel importante do uso de analogias ou simulações na construção de modelos e desenvolvimento do raciocínio com consequentes ganhos para a compreensão do assunto. ${ }^{21-23}$

No caso de disciplinas introdutórias, nas quais o assunto exige uma abordagem matemática (como no caso de soluções tampão), algumas recomendações podem ser feitas com base nos resultados do presente estudo. A noção de que um equilíbrio dinâmico se estabelece em determinados sistemas químicos e que a composição da solução é função da constante de equilíbrio e das concentrações inicias dos reagentes parece ser bem difundida entre os estudantes. Entretanto, ao se perturbar o equilíbrio pela adição de substâncias químicas observam-se evidentes dificuldades na resolução dos problemas e estes estão associados, num primeiro instante, com a falta de clareza sobre a correlação entre os termos volume de solução, quantidade de matéria (mols) e concentração. A confusão existe porque o conceito de "mol" é abstrato, e não é claro para os alunos que se trata de uma unidade associada à grandeza "quantidade de matéria". Assim, muitos alunos não veem diferença entre as unidades mol e mol L $\mathrm{L}^{-1}$, e quando o volume de solução é $1 \mathrm{~L}$ a confusão pode ficar ainda mais reforçada.

Dúvidas sobre a natureza da reação entre o reagente adicionado e as espécies químicas em solução foram exaustivamente evidenciadas no convívio com os estudantes e constituem-se em problema claramente vinculado à imaturidade e limitações naturais oriundas do restrito conhecimento químico no caso de alunos ingressantes. A etapa seguinte na resolução de questões deste tipo é provavelmente a mais complexa, visto que ela exige dos estudantes a noção de mudança na composição do sistema e acomodação a uma nova situação de equilíbrio. Exemplos clássicos envolvem a mudança de $\mathrm{pH}$ de uma solução tampão após a adição de determinada quantidade de ácido ou base forte. Uma ferramenta útil para o encaminhamento deste assunto baseia-se no uso de diagramas de distribuição de espécies, em que a caracterização do sistema químico é feita em função de uma variável independente (neste caso, o pH).

Para finalizar, cabe ressaltar o importante papel de atividades práticas no aprendizado deste tema. Especificamente no caso de soluções tampão, experimentos envolvendo a preparação de soluções com essa característica, partindo de soluções de acetato de sódio ou cloreto de amônio, são muitos úteis, pois a tarefa pode ser realizada de diversas maneiras, quer seja adicionando-se ácido/base fracos conjugados ou partindo-se de soluções de ácidos e bases fortes com neutralização parcial dos sais. Este tipo de atividade é importante, pois desenvolve habilidades práticas no manuseio de soluções e exige do aluno o trabalho com grandezas como concentração, volume e quantidade de matéria, além de facilitar a compreensão das propriedades das soluções tampão.

\section{AGRADECIMENTOS}

Ao CNPq pela bolsa de Produtividade em Pesquisa e aos professores, monitores e estudantes envolvidos na disciplina Fundamentos da Química - Transformações no $1^{\circ}$ semestre de 2007.

\section{REFERÊNCIAS}

1. Jonhstone, A. H.; Education in Chemistry 1977, 14, 169

2. Pereira, M. P. B. A.; Quim. Nova 1989, 12, 76.

3. Machado, A. H.; Aragão, R. M. R.; Química Nova na Escola 1996, nº 4, 18.

4. Tyson, L.; Treagust, D. F.; Bucat, R. B.; J. Chem. Educ. 1999, 76, 554.

5. Júnior, J. G. T.; Silva, R. M. G.; Resumos da 29a Reunião Anual da Sociedade Brasileira de Química, Águas de Lindóia, Brasil, 2005.

6. Sabadini, E.; Bianchi, J. C. A.; Química Nova na Escola 2007, n 25, 10.

7. Souza, K. A. F. D.; Cardoso, A. A.; Química Nova na Escola 2008, nº $27,51$.

8. Fernandez, C.; Baldinato, J. O.; Tiedemann, P.; Bertotti, M.; Quim. Nova 2008, 31, 1582 .

9. Bergquist, W.; Heikkinen, H.; J. Chem. Educ. 1990, 67, 1000.

10. Rudd, J. A.; Greenbowe, T. J.; Hand, B. M.; Legg, M. J.; J. Chem. Educ. 2001, 78, 1680 .

11. Gillespie, R. J.; J. Chem. Educ. 1991, 68, 192.

12. Sandberg, M.; Bellamy, M. K.; J. Chem. Educ. 2003, 80, 456.

13. Hawkes, S. J.; J. Chem. Educ. 2003, 80, 1381.

14. Moreno, E. L.; Rajagopal, K.; Quim. Nova 2009, 32, 538.

15. De Oliveira, W.; Tiedemann, P. W.; Cecchini, R. G.; Osorio, V. K. L.; Quim. Nova 2009, 32, 1064.

16. Gama, M. D. S.; Afonso. J. C.; Quim. Nova 2007, 30, 232.

17. Cunha, A. M.; Tunes, E.; Silva, R. R.; Quim. Nova 2001, 24, 262.

18. Meites, L.; Pode, J. S. F.; Thomas, H. C.; J. Chem. Educ. 1966, 43, 667.

19. Gillispie, G. D.; J. Chem. Educ. 1990, 67, 143.

20. Hawkes, S.; J. Chem. Educ. 1998, 75, 1179.

21. Mendonça, P. C. C.; Justi, R. S.; Poliana, E. M.; Enseñanza de Las Ciencias 2005, Número Extra, VII Congresso Internacional, 1.

22. Raviolo, A.; Garritz, A.; Química Nova na Escola 2008, n 27, 13.

23. Huddle, P. A.; White, M. W.; J. Chem. Educ. 2000, 77, 920. 